\title{
Brief Report: The Identity Style Inventory (ISI-3) and the Utrecht-Management of Identity Commitments Scale (U-MICS): Factor structure, reliability, and convergent validity in French-speaking university students
}

\author{
Grégoire Zimmermann, Elodie Biermann Mahaim, and Gregory Mantzouranis \\ LabDCI, Institute of Psychology, University of Lausanne, Switzerland \\ Philippe A. Genoud \\ Department of Psychology, University of Fribourg, Switzerland \\ Elisabetta Crocetti \\ Department of Educational Sciences, University of Macerata, Italy
}

\author{
Author Note
}

Correspondence concerning this article should be addressed to Grégoire Zimmermann, LabDCI, Institute of Psychology, University of Lausanne, Bâtiment Antropole, CH-1015 Lausanne, Switzerland. Tel.: +41 (0)21 69232 60, Fax: +41 (0)21 69232 65, E-mail: Gregoire.Zimmermann@unil.ch

The authors would like to thank the students who kindly volunteered to participate in the study. We also thank Marjorie Grivel for assistance with data processing, and Valérie Rossier for assistance with translation.

This is an unedited manuscript published in the Journal of Adolescence Please note that the published version has undergone minor additional editing in style and content. Please cite as:

Zimmermann, G., Biermann-Mahaim, E., Mantzouranis, G., Genoud P. A., \& Crocetti, E. (2012). The Identity Style Inventory (ISI-3) and the Utrecht-Management of Identity Commitment Scale (U-MICS): Factor structure, reliability, and convergent validity in French-speaking college students. Journal of Adolescence, 35(2), 461-465. doi: $10.1016 /$ j.adolescence.2010.11.013 


\begin{abstract}
The purpose of this study was to evaluate the factor structure and the reliability of the French versions of the Identity Style Inventory (ISI-3) and the Utrecht-Management of Identity Commitments Scale (U-MICS) in a sample of college students ( $\mathrm{N}=457,18$ to 25 years old). Confirmatory factor analyses confirmed the hypothesized three-factor solution of the ISI-3 identity styles (i.e. informational, normative, and diffuse-avoidant styles), the onefactor solution of the ISI-3 identity commitment, and the three-factor structure of the U-MICS (i.e. commitment, in-depth exploration, and reconsideration of commitment). Additionally, theoretically consistent and meaningful associations among the ISI-3, U-MICS, and Ego Identity Process Questionnaire (EIPQ) confirmed convergent validity. Overall, the results of the present study indicate that the French versions of the ISI-3 and UMICS are useful instruments for assessing identity styles and processes, and provide additional support to the cross-cultural validity of these tools.
\end{abstract}




\section{Introduction}

In his classic developmental theory, Erikson (1968) outlined that identity formation is a dynamic life-long process, which becomes a central developmental task during adolescence and the transition to adulthood (Arnett, 2000). Marcia's identity status model (1966) has been the most important paradigm in the neo-Eriksonian identity research. However, research in Marcia's status paradigm has been more focused on categorizing adolescents into statuses than on studying the process of identity development. Therefore, several scholars have extended Marcia's conceptualizations by proposing models focused on the processes underpinning personal identity formation (cf. Schwartz, 2001). For example, Berzonsky $(1989,2004)$ and Meeus (1996) proposed new theoretical insights to identity formation, including efforts to extent conceptualization and operationalization of the process of exploration. Both approaches are process-oriented, that is they play attention on the dynamics by which identity is constructed and changed over time. However, the two models diverge from one another, since they focus on different dimensions. Berzonsky's approach focuses on the role of social-cognitive orientations (i.e. identity styles) that individuals rely on when they deal with identity issues, whereas Meeus's approach, more grounded in Marcia's status paradigm, focuses on the type of exploration that adolescents use in the dynamic of their identity construction.

In particular, Berzonsky (1989) has proposed a social-cognitive model focused on identity styles (i.e. informational, normative, and diffuse-avoidant styles) that represent differences in strategies used by individuals to deal with life choices and identity issues. Specifically, adolescents with an informational identity style are self-reflective and they actively seek out and evaluate self-relevant information. Individuals who have a normative style mainly adopt prescriptions and values of significant others and conform to their 
expectations. Finally, young people with a diffuse-avoidant style procrastinate and delay dealing with identity issues as long as possible (Berzonsky, 1989). Accordingly, Berzonsky (1992) developed the Identity Style Inventory (ISI) to assess the styles that individuals prefer to use, as well as the strength of their identity commitment. Although the ISI has been used in diverse cultural contexts (Berzonsky, 2004), it has not been used in a French-speaking context.

Recently, based on previous works of Meeus (1996), Crocetti, Rubini, and Meeus (2008), also expanded Marcia's paradigm and proposed a three-dimensional identity model with commitment, in-depth exploration, and reconsideration of commitment as critical identity processes. Specifically, commitment refers to firm choices that adolescents have enacted with regard to various developmental domains and to the self-confidence they derive from these choices; in-depth exploration represents the extent to which adolescents reflect on their current commitments, search for additional information, and talk with others about their choices; and reconsideration of commitment refers to the possibility of discarding or revising one's current commitments when they are no longer satisfactory. This latter dimension encompasses loosening existing commitments with exploration in breadth of new identity alternatives. To measure these processes, Meeus developed the Utrecht-Management of Identity Commitments Scale (U-MICS; Crocetti, Rubini, \& Meeus, 2008). Up to now, this measure has been used with adolescents in the Netherlands (e.g., Crocetti et al., 2008) and Italy (Crocetti, Schwartz, Fermani, \& Meeus, 2010) and no studies have been reported in other national and cultural contexts.

Therefore, the aim of our study was to translate and assess factorial and convergent validity and reliability of French versions of the ISI-3 and the U-MICS.

\section{Method}

\section{Participants}


Our sample consisted of 457 undergraduate students (380 women, 77 men) mainly from Faculties of Psychology and Social Sciences of three universities in the French-speaking part of Switzerland. The mean age of this sample was 21.77 years $(S D=2.08)$, with $95 \%$ of the sample aged between 18 and 25 years. In terms of nationality, $88.6 \%$ were Swiss citizens, $10.3 \%$ were citizens of another European Community country and $1.1 \%$ were citizens of a non-European country.

\section{Measures}

Identity Style Inventory (ISI-3)

The ISI-3 (Bersonsky, 1992) is a 40-item scale rated on a 5-point Likert scale ranging from 1 (not at all like me) to 5 (very much like me) that assesses three identity styles (informational, 11 items; normative, 9 items; diffuse-avoidant, 10 items) and identity commitment (10 items). Utrecht-Management of Identity Commitments Scale (U-MICS)

The U-MICS (Crocetti, et al., 2008, 2010), is a 13-item questionnaire rated on a 5-point Likert scale ranging from 1 (completely untrue) to 5 (completely true), that assesses three identity processes (commitment, 5 items; in-depth exploration, 5 items; and reconsideration of commitment, 3 items). The same items can be filled out to assess identity dimensions in different domains. In this study one ideological (i.e. education) and one interpersonal (i.e. friendships) domain were considered.

Short Form of the Ego Identity Process Questionnaire (EIPQ-SF)

Derived from the EIPQ (Balistreri et al., 1995), the EIPQ-SF is a 16-item questionnaire rated on 6-point Likert scale ranging from 1 (strongly disagree) to 6 (strongly agree) that assesses identity exploration and identity commitment in the ideological and interpersonal areas (French validation by Zimmermann, Mantzouranis, \& Biermann, 2010).

\section{Procedure}

The items of the U-MICS and ISI-3 were translated from English to French by three 
independent psychologists according to the recommendations of the International Test commission (Hambleton, 2001). All discrepancies identified between the three versions of each questionnaire were discussed with the first author until a consensus was reached to develop a final single version of the U-MICS and the ISI-3. On this basis, a bilingual translator back translated the French versions to English. This back translation procedure provided English versions identical in content with the original items of the ISI-3 and UMICS.

\section{Results and Discussion}

\section{Factor structure of the ISI-3 and the U-MICS}

To test the factor structure of the French versions of the ISI-3 and the U-MICS, Confirmatory Factor Analyses (CFAs) were conducted on the variance-covariance matrix using maximum likelihood estimation through R-software (version 2.1.1, May 2010). For both scales, we used a parcelling approach (random assignment of items to parcels) as recommended by Crocetti and colleagues $(2009,2010)$ in the Italian validation of these two scales. Specifically, we used nine parcels for the ISI-3 identity style factors (i.e., three parcels for each identity style), four parcels for the ISI-3 commitment mono-factor, and nine parcels for the U-MICS (i.e., three parcels for each latent factor).

We evaluated the fit of these models using various fit indices including the goodness-of-fit index (GFI), the adjusted goodness-of-fit index (AGFI), the comparative fit index (CFI), the standardized root mean square residual (SRMR), and the root mean square error of approximation (RMSEA). Specifically, these indexes have been considered as indicators of good fit when GFI, AGFI and the CFI values are greater than or equal to .90 (Bentler, \& Bonnett, 1980; Cole, 1987). For the RMSEA and SRMR values of .08 or less and of .09 or less would respectively indicate a reasonable fit (Browne \& Cudeck, 1993; Hu \& Bentler, 1999). 
Fit indices reported in Table 1 indicated that: (1) the three-factor solution of the ISI-3 identity styles and the one-factor solution of the ISI-3 identity commitment provided respectively a good and an excellent fit to the data, with significant factor loadings (standardized regression weights) ranging from 0.24 to 0.85 and 0.31 to 0.88 for the identity style three-factor and commitment one-factor models, respectively; and (2) the three-factor model of the U-MICS showed an acceptable fit ${ }^{1}$, with significant factor loadings ranging from 0.39 to 1.27 .

These findings should be considered in the light of a particular limitation. In fact, the sample of college students that we used to confirm the structure of the ISI-3 and U-MICS consisted primarily of female late adolescents ( $83.2 \%$ of the sample), mirroring the unbalanced distribution of gender usually observed in social sciences and psychology students. Thus, it is not known whether the results would have been different if a more gender-balanced sample had been used, and further research is needed to assess structure invariance across gender.

\section{Subscales intercorrelations}

For the ISI-3, as already observed (e.g., Crocetti, et al., 2009), the informational style was positively associated with the normative style $(r=.11, p<.05)$ and negatively with the diffuse-avoidant style $(r=-.20, p<.001)$. The diffuse-avoidant and normative styles were unrelated. Additionally, as theoretically expected (Berzonsky, 2003), ISI-3 commitment was positively linked to the informational $(r=.33, p<.001)$ and normative styles $(r=.41$, $p<.001)$, and negatively associated with the diffuse-avoidant style $(r=-.32, p<.001)$.

Consistent with previous studies about U-MICS (Crocetti, et al., 2008, 2010), commitment was positively associated with in-depth exploration $(r=.43, p<.001)$, suggesting that college students with strong current commitments continue to reflect on their choices (Meeus,

\footnotetext{
${ }^{1}$ Results of separate CFA's for ideological and interpersonal domains of the U-MICS showed excellent fit to the data (Ideological: GFI=.98, AGFI $=.96$, CFI $=.98$, SRMR $=.04$, RMSEA $=.05$ (90\% CI: .03-.08) / Interpersonal: $\mathrm{GFI}=.97, \mathrm{AGFI}=.93, \mathrm{CFI}=.98, \mathrm{SRMR}=.05, \mathrm{RMSEA}=.07(90 \% \mathrm{CI}: .05-.09))$.
} 
Iedema, \& Maassen, 2002). Contrary to what was observed in early and middle adolescent samples, commitment was negatively related to reconsideration of commitment $(r=-.26$, $p<.001)$, indicating as hypothesized by Crocetti et al. $(2008,2010)$ that when growing older, individuals hold stronger commitments and are less prone to think about other identity alternatives. Finally, reconsideration of commitment was not associated with in-depth exploration, whereas prior studies (Crocetti et al., 2008, 2010) evidenced a small association between these two processes. This latter result suggests that, in late adolescence, youth who are consolidating their commitments are less likely to gather at the same time information about commitment alternatives.

\section{Reliability of the ISI-3 and U-MICS}

For the ISI-3, Cronbach alphas were $.62, .65, .69$ for the informational, normative, and diffuse-avoidant styles, respectively, and .74 for commitment. These values are comparable to those reported in previous studies (e.g., Berzonsky \& Kinney, 2008; Soenens, Duriez, \& Goossens, 2005). Concerning the U-MICS, alphas for commitment, in-depth exploration, and reconsideration of commitment were respectively $.84, .72$ and .75 , which are similar to those of the original version (Crocetti, et al., 2010).

\section{Convergent validity}

Relationships between identity styles (ISI-3), U-MICS identity processes, and EIPQ-SF dimensions (see Table 2) were in line with those reported in the literature. Specifically, regarding the associations between the ISI-3 and U-MICS factors, findings revealed that the informational style was positively related to commitment and, to a stronger extent, to in-depth exploration; the normative style was positively associated with commitment, and to a smaller extent to in-depth exploration; and the diffuse-avoidant style was negatively associated with in-depth exploration and positively related, but to a small extent, to reconsideration of commitment. Overall, these findings, in line with available literature (Berzonsky, 2004; 
Crocetti et al., 2009), indicate that informational style is associated to identity work that can lead to identity maturity, that normative style is linked to firm commitments and identity stability, and finally that the diffuse-avoidant style is associated with a condition of identity uncertainty. This latter result underlines that reconsideration of commitment assessed by UMICS is not only characterized by individual's attempt to change current commitments. It also reflects the troublesome aspect of identity formation associated with a sense of disequilibrium, distress, and doubt, which is characteristic of individuals with high diffuse avoidant style scores (Berzonsky, 2004; Crocetti, et al., 2008, 2010). Furthermore, as already reported in the literature (Crocetti et al., 2009) the ISI-3 commitment was positively related to U-MICS commitment and in-depth exploration, and negatively linked to reconsideration of commitment.

Regarding the associations among ISI-3 and EIPQ-SF factors, results indicated, in line with previous results obtained in other European and North-American contexts (e.g., Berman, Schwartz, Kurtiness, \& Berman, 2001; Luyckx, Goossens, Beyers, \& Soenens, 2006) that the informational style, as well as ISI-3 commitment, were positively related to EIPQ-SF commitment and exploration; the normative style was positively related only to commitment, and the diffuse-avoidant style was negatively linked to both commitment and exploration.

Finally, associations among U-MICS and EIPQ-SF dimensions, examined for the first time in this study, provided further support to the U-MICS convergent validity. In fact, U-MICS commitment was positively related to EIPQ-SF commitment; U-MICS in-depth exploration was positively related to EIPQ-SF commitment and to a stronger extent to EIPQ-SF exploration; and reconsideration of commitment was negatively linked to EIPQ-SF commitment and positively associated with EIPQ-SF exploration.

\section{Conclusion}

The results of this study provide preliminary evidence of the factorial, reliability, and 
convergent validity of the French versions of the ISI-3 and U-MICS. Thus, the French versions of the ISI-3 and U-MICS appear to be useful instruments for identity research in a French-speaking context, providing additional support to the cross-cultural validity of both tools. 


\section{References}

Arnett, J. J. (2000). Emerging adulthood: A theory of development from the late teens through the twenties. American Psychologist, 55, 469-480. doi: 10.1037//0003066X.55.5.469

Bentler, P.M ., \& Bonnett, D. G. (1980). Significance tests and goodness of fit in the analysis of covariance structures. Psychological Bulletin, 88, 588-606. doi:10.1037/00332909.88.3.588

Berman, A. M., Schwartz, S. J., Kurtines, W. M., \& Berman, S. L. (2001). The process of exploration in identity formation: the role of style and competence. Journal of Adolescence, 24(4), 513-528. doi:10.1006/jado.2001.0386

Berzonsky, M. D. (1989). Identity style: Conceptualization and measurement. Journal of Adolescent Research, 4, 267 - 281. doi:10.1177/074355488943002

Berzonsky, M. D. (2003). Identity style and well-being: Does commitment matter? Identity: An International Journal of Theory and Research, 3, 131-142. doi :10.1207/S1532706XID030203

Berzonsky, M. D. (2004). Identity processing style, self-construction, and personal epistemic assumptions: A social-cognitive perspective. European Journal of Developmental Psychology, 1(4), 303. doi:10.1080/17405620444000120

Berzonsky, M. D., \& Kinney, A. (2008). Identity processing style and defense mechanisms. Polish Psychological Bulletin. 39(3), 111-117. doi: 10.2478/v10059-008-0022-7

Browne, M. W., \& Cudeck, R. (1993). Alternative ways of assessing model fit. In K. A. Bollen \& S. J. Long (Eds.), Testing structural equation models (pp. 136-162). Newbury Park, CA: Sage.

Cole, D. A., 1987. Utility of confirmatory factor analysis in test validation research. Journal of Consulting and Clinical Psychology, 55(4), 584-954. doi: 10.1037/0022006X.55.4.584

Crocetti, E., Rubini, M., Berzonsky, M. D., \& Meeus, W. (2009). Brief report: The Identity Style Inventory - Validation in Italian adolescents and college students. Journal of Adolescence, 32(2), 425-433. doi:10.1016/j.adolescence.2008.04.002 
Crocetti, E., Rubini, M., \& Meeus, W. (2008). Capturing the dynamics of identity formation in various ethnic groups: Development and validation of a three-dimensional model. Journal of Adolescence, 31(2), 207-222. doi:10.1016/j.adolescence.2007.09.002

Crocetti, E., Schwartz, S., Fermani, A., Meeus, W. (2010). The Utrecht Management of Identity Commitment Scale (U-MICS): Italian validation and cross-national comparisons. European Journal of Psychological Assessment, 26, 169-183. doi: $10.1027 / 1015-5759 / \mathrm{a} 000024$

Erikson, E. H. (1968). Identity, youth and crisis. New York: Norton.

Hambleton, R. K. (2001). The next generation of ITC test translation and adaptation guidelines. European Journal of Psychological Assessment, 17, 164-172. doi: $10.1027 / / 1015-5759.17 .3 .164$

Luyckx, K., Goossens, L., Beyers, W., \& Soenens, B. (2006). Brief report: The ego identity process questionnaire: Factor structure, reliability, and convergent validity in Dutchspeaking late adolescents. Journal of Adolescence, 29(1), 153-159. doi:10.1016/j.adolescence.2005.03.006

Marcia, J. E. (1966). Development and validation of ego-identity status. Journal of Personality and Social Psychology, 3, 551-558. doi: 10.1037/h0023281

Meeus, W. (1996). Studies on identity development in adolescence: An overview of research and some new data. Journal of Youth and Adolescence, 25(5), 569-598. doi:10.1007/BF01537355

Meeus ,W., Iedema, J., \& Maassen, G. H. (2002). Commitment and exploration as mechanisms of identity formation. Psychological Reports, 90, 771-785.

$\mathrm{R}$ development Core Team (2010). R: A language and environment for statistical computing. Vienna, Austria: The R Fondation for Statistical Computing (http://www.rproject.org/).

Schwartz, S. J. (2001). The evolution of Eriksonian and, Neo-Eriksonian identity theory and research: A review and integration. Identity: An International Journal of Theory and Research, 1, 7-58. doi:10.1207/S1532706XSCHWARTZ

Soenens, B., Duriez, B., \& Goossens, L. (2005). Social-psychological profiles of identity styles: Attitudinal and socialcognitive correlates in late adolescence. Journal of Adolescence, 28, 107-125. doi:10.1016/j.adolescence.2004.07.001 
Zimmermann, G., Mantzouranis, G., \& Biermann, E. (2010). Ego identity in adolescence: Preliminary validation of a French short-form of the EIPQ. Revue Européenne de Psychologie Appliquée/European Review of Applied Psychology, 60(3), 173-180. doi:10.1016/j.erap.2010.01.001 
Running head: ISI-3 and U-MICS FRENCH VALIDATION

Table $1:$ Fit indices for the UMICS and ISI-3

$\begin{array}{lllll}\text { GFI } & \text { AGFI } & \text { CFI } & \text { SRMR } & \text { RMSEA (90\% CI) }\end{array}$

ISI-3

Identity styles

$\begin{array}{lllll}.96 & .93 & .90 & .05 & .07(.05-.09)\end{array}$

(3-factor model)

Commitment

$\begin{array}{lllll}.99 & .99 & 1.00 & .01 & .00(.00-.08)\end{array}$

(1-factor model)

U-MICS

3-factor model

.95

.91

.95

.07

$.09(.07-.10)$ 
Table 2 : Bivariate correlations between ISI identity styles, ISI commitment, U-MICS identity dimensions and EIPQ-SF exploration and commitment

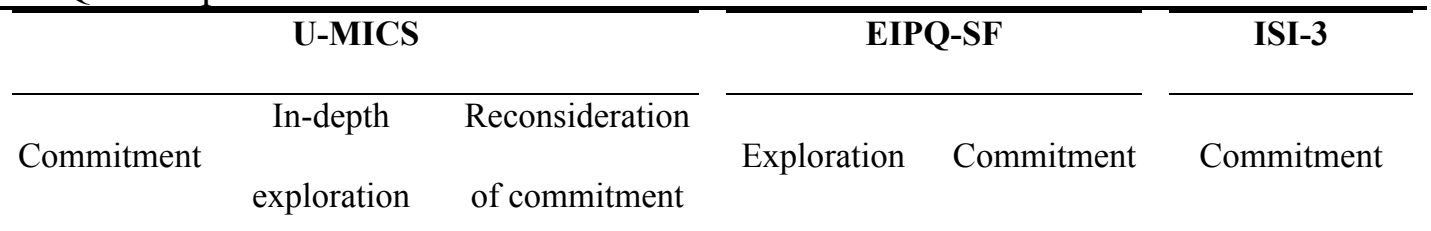

\begin{tabular}{|c|c|c|c|c|c|c|}
\hline \multicolumn{7}{|l|}{ ISI-3 } \\
\hline Informational & $.18^{* * *}$ & $.44^{* * *}$ & .09 & $.47^{* * *}$ & $.14^{* * *}$ & $.33^{* * *}$ \\
\hline Normative & $.29^{* * *}$ & $.15^{* *}$ & .00 & -.04 & $.39^{* * *}$ & $.41^{* * *}$ \\
\hline Diffuse-avoidant & -.09 & $-.12^{*}$ & $.18^{* * *}$ & $-.15^{* *}$ & $-.16^{* *}$ & $-.32^{* * *}$ \\
\hline Commitment & $.38^{* * *}$ & $.21^{* * *}$ & $-.17^{* * *}$ & $.17^{* * *}$ & $.52^{* * *}$ & 1 \\
\hline \multicolumn{7}{|l|}{ U-MICS } \\
\hline Commitment & 1 & $.43^{* * *}$ & $-.26^{* * *}$ & .08 & $.27^{* * *}$ & $.38^{* * *}$ \\
\hline In-depth explor. & - & 1 & .04 & $.31^{* * *}$ & $.20^{* * *}$ & $.21^{* * *}$ \\
\hline Recons. commit. & - & - & 1 & $.11^{*}$ & $-.14^{* *}$ & $-.17^{* * *}$ \\
\hline
\end{tabular}

Note. ${ }^{*} p<.05,{ }^{* *} p<.01,{ }^{* * *} p<.001$. 